\title{
O ESPORTE EDUCACIONAL FORMANDO CRIANÇAS NAS AULAS DE EDUCAÇÃO FÍSICA NO ENSINO FUNDAMENTAL ॥
}

\section{Patrícia Gonçalves da Silva ${ }^{1}$ Daniela Moraes Scoss ${ }^{2}$}

Resumo: A presente revisão de literatura traz como propósito o conhecimento da contribuição do esporte educacional no desenvolvimento de crianças durante as aulas de educação física no ensino fundamental II. A escola, tem como objetivo formar os alunos para a sociedade. O esporte educacional, por sua vez, tem o mesmo objetivo e utiliza o esporte como um meio para que haja a progressão em busca dessa formação. Portanto nas aulas de Educação Física Escolar, o esporte deve ser utilizado como um meio de aprendizagem educacional desses alunos, visando o desenvolvimento motor (procedimental), desenvolvimento cognitivo (conceitual) e o desenvolvimento sócio-afetivo (atitudinal). Sendo assim, compreende-se que o aluno está sendo desenvolvido de forma integral.

Palavras-chave: Esporte educacional; Ensino fundamental II; Educação física escolar; formação integral.

\footnotetext{
${ }^{1}$ Educação Física/Centro Universitário Ítalo Brasileiro, Brasil. E-mail: patty.goncalves@yahoo.com.

2 Educação Física/Centro Universitário Ítalo Brasileiro, Brasil. E-mail: danielascoss@gmail.com.
} 